\title{
General Equilibrium Analysis on Arms Exports to Developing Countries in Conflict
}

\author{
$\underline{\text { T. Fukiharu }}$ \\ Faculty of Economics, Hiroshima University, Japan (fukito@hiroshima-u.ac.jp)
}

\begin{abstract}
In this paper a conflict game between the two developing countries is constructed. It is assumed that all the weapons are imported at the fixed world price, $p_{M}$, and the consequence of the decline of $p_{M}$ is examined. In specifying the utility and production functions in general equilibrium (GE) model by Cobb-Douglass type, we actually derive the reaction functions of GE conflict game. We examine the effect of the decline of $p_{M}$ on the "existence" of solution to the game, its "stability", and finally on the utility levels of two countries in the "stability" case. The special feature of the model is each country's armed forces cause external diseconomy to the other's production. By constructing 10000 games, we show that as $p_{M}$ falls, the number of "non-existence" cases increases, the percentage of "instability" cases rises, and finally as $p_{M}$ falls, the percentage of "rising utility levels of both countries" cases. Finally we derive the reaction functions in this conflict game when two countries have domestic military industries.
\end{abstract}

Keywords: conflict game, general equilibrium, existence, stability, simulation.

\section{INTRODUCTION}

After the collapse of Berlin Wall in 1989 the Eastern bloc began to disintegrate itself, resulting in the disappearance of USSR in 1991. On the one hand, the victory of Western bloc forced the other bloc to reconstruct its economy through introduction of market mechanism. On the other hand, the defeat of the Eastern bloc unleashed racial conflicts: e.g. the one in Yugoslavia. In Galbraith [1994], he urged mainstream economists to incorporate military factors into the traditional civilian economic models, especially, the "arms trade to the poor countries of the planet: a trade that denies people the first essentials of survival and supports the most egregious of human slaughter" (p.9). According to him, "in the eight years from 1981 to 1989 , the less developed countries (LDCs) acquired from various sources 37000 surface-to air missiles, 20000 artillery pieces, 11000 tanks and self-propelled howitzers, 3200 supersonic planes and 540 warships and submarines at a cost of \$354.6 billion" (p.11).

The aim of this paper is to respond to the urging by Galbraith, by extending Fukiharu [1990], in which weapons essentially consist of sticks and stones. In this paper, we start with the assumption that there are two LDCs, whose armed forces consist of troops and imported weapons (from the advanced countries). Since these LDCs are small countries, it is assumed that weapons are imported at the fixed world price, $p_{M}$. As the result of the collapse of communist countries with redundant weaponry, $p_{M}$ may tend to decline. The consequence of the decline of $p_{M}$ is examined. Specifying the utility and production functions by Cobb-Douglass type, we actually derive the reaction functions of conflict game with modified definition of armed forces. It is revealed that they are non-linear, while in Fukiharu [1990, SECTION III], they are linear.

\section{TWO LDC MODEL WITH ARMS TRADE}

In this section, we formulate a two-country model in which two confronting countries intentionally exert external diseconomy upon each other: i.e., they are at war with each other. On this subject, one of the pioneers is Lewis F. Richardson, a Quaker physicist, who studied the causes and origins of war through mathematical modeling. His pioneering contributions were collected in Richardson [1960], which essentially consists of simple differential equations. Let $D_{1}$ and $D_{2}$ be national defense levels of two countries. It is assumed that $D_{1}$ and $D_{2}$ change on the following differential equations:

$$
\begin{aligned}
& \mathrm{d} D_{1} / \mathrm{d} t=\kappa_{1} D_{2}-\varphi_{1} D_{1}+v_{1}, \\
& \mathrm{~d} D_{2} / \mathrm{d} t=\kappa_{2} D_{1}-\varphi_{2} D_{2}+v_{2},
\end{aligned}
$$


where $\kappa_{1}$ and $\kappa_{2}$ are positive defense coefficients, while $\varphi_{1}$ and $\varphi_{2}$ represent the fatigue and expense of keeping up defenses. It is shown that if

$$
\varphi_{1} \varphi_{2}>\kappa_{1} \kappa_{2}
$$

holds, the system of differential equations is stable, while otherwise it is unstable. It was examined later, whether simple formulation as in (1) and (2) could explain an actual arms race, with the conclusion that at the starting point of an arms race beginning in 1908, the system had direction for war: unstable.

The spirit of his research was subsequently succeeded and was expanded with the help of game theory: e.g. see Rapoport [1968]. Our purpose in this section is to examine how coefficients such as $\kappa_{i} \mathrm{~S}$ and $\varphi_{i} \mathrm{~s}$ in (1) and (2) are determined in a two-country model with each bloc maximizing utility, and how they change by the shift in parameters of the model.

In the model, constructed below, the aim of (aggregate) household of the 1-st country with initial endowment of labor, $\bar{l}_{1}$, is the utility maximization:

$$
\begin{gathered}
\max U_{1}\left(x_{1}, z_{1}\right)=x_{1}^{\alpha 1} z_{1}{ }^{1-\alpha 1} \quad 0 \leqq \alpha_{1} \leqq 1 \\
\text { s.t. } z_{1}=m_{1}{ }^{\gamma 1} v_{1}{ }^{1-\gamma 1}, 0 \leqq \gamma_{1} \leqq 1 \\
p_{1} x_{1}+p_{M} m_{1}=W_{1}\left(\bar{l}_{1-v_{1}}\right)+\pi_{1}
\end{gathered}
$$

where $x_{i}$ is the $i$-th country's consumption of civilian goods with $p_{i}$ commodity price, and $z_{i}$ is the $i$-th country's military power (defense level), consisting of manpower (troops), $v_{i}$, and weapons, $m_{i}$, imported from the developed countries, with "fixed" price $p_{M}$, while $W_{i}$ is the wage rate and $\pi_{i}$ is the profit from the domestic firm. $(i=1,2)$ In this section, it is assumed that $p_{i}$ is "fixed"; i.e. determined in the international market. The firm of the 1-st country, producing the civilian good, aims at profit maximization, given the effect of the invasion of foreign country:

$$
\max \pi_{1}=p_{1} f_{1}\left(L_{1}, z_{2}\right)-W_{1} L_{1},
$$

where $\quad f_{1}\left(L_{1}, z_{2}\right)=\left(L_{1}-\lambda_{1} z_{2}\right)^{\beta 1}, \quad 0 \leqq \beta_{1} \leqq 1, \quad$ is production function, $L_{1}$ is labor input, and $\lambda_{1}$ is the enemy's invasion effect on production facility, such as farm land: the degree of external diseconomy. Given $z_{2}, p_{1}$, and $W_{1}$, maximizing behavior of the 1-st firm gives rise to labor demand, $L_{1}{ }^{\mathrm{d}}$, commodity supply, $x_{1}^{\mathrm{s}}$, and profit, $\pi_{1} / p_{1}$.

Solving the domestic general equilibrium with arms trade with developed countries for the country 1 , her armed force, $z_{1}$, given $z_{2}$, is derived as

$$
\begin{aligned}
& z_{1}=\psi_{1}\left(z_{2}\right)=\gamma_{1}{ }^{\gamma 1}\left(1-\alpha_{1}\right)\left(1-\gamma_{1}\right)^{1-\gamma 1} \beta_{1}{ }^{\beta 1} \gamma 1 \\
& \left\{\alpha_{1}+\gamma_{1}\left(1-\alpha_{1}\right)\right\}^{\gamma 1(\beta 1-1)}\left(\bar{l}_{1}-\lambda_{1} z_{2}\right){ }^{(1-\gamma 1)+\beta 1 \gamma 1} \\
& \left(p_{1} / p_{M}\right)^{\gamma 1} /\left[1-\left\{\alpha_{1}+\gamma_{1}\left(1-\alpha_{1}\right)\right\}\left(1-\beta_{1}\right)\right]^{(1-\gamma 1)+\beta 1 \gamma 1}
\end{aligned}
$$

which is the (non-cooperative) reaction function of the 1-st country. (For the derivation of this reaction function, see my home page, http://home.hiroshima-u.ac.jp/fukito/index.htm.) Meanwhile, the (aggregate) household of the 2-nd country with initial endowment of labor, $\bar{l}_{2}$, maximizes utility

$$
\begin{gathered}
U_{2}\left(x_{2}, z_{2}\right)=x_{2}{ }^{\alpha 2} z_{2}{ }^{1-\alpha 2}, \quad 0 \leqq \alpha_{2} \leqq 1 \\
\text { s.t. } z_{2}=m_{2}{ }^{\gamma 2} v_{2}{ }^{1-\gamma 2}, 0 \leqq \gamma_{2} \leqq 1, \\
p_{2} x_{2}+p_{M} m_{2}=W_{2}\left(\bar{l}_{2}-v_{2}\right)+\pi_{2},
\end{gathered}
$$

The civilian goods producing firm of the 2-nd country maximizes profit

$$
\pi_{2}=p_{2} f_{2}\left(L_{2}, z_{1}\right)-W_{2} L_{2},
$$

where $\quad f_{2}\left(L_{2}, z_{1}\right)=\left(L_{2}-\lambda_{2} z_{1}\right)^{\beta 2}, \quad 0 \leqq \beta_{2} \leqq 1, \quad$ is production function, $L_{2}$ is labor input, and $\lambda_{2}$ is the 1-st country's invasion effect on production facility: the degree of external diseconomy. In exactly the same way, the (non-cooperative) reaction function of the 2-nd country is given by

$$
\begin{aligned}
z_{2}= & \psi_{2}\left(z_{1}\right)=\gamma_{2}{ }^{\gamma 2}\left(1-\alpha_{2}\right)\left(1-\gamma_{2}\right)^{1-\gamma 2} \beta_{2}{ }^{\beta 2 \gamma 2} \\
& \left\{\alpha_{2}+\gamma_{2}\left(1-\alpha_{2}\right)\right\}^{\gamma 2(\beta 2-1)}\left(\bar{l}_{2} \lambda_{2} z_{1}\right)^{(1-\gamma 2)+\beta 2 \gamma 2} \\
& \left(p_{2} / p_{M}\right)^{\gamma 2} /\left[1-\left\{\alpha_{2}+\gamma_{2}\left(1-\alpha_{2}\right)\right\}\left(1-\beta_{2}\right)\right]^{(1-\gamma 2)+\beta 2 \gamma 2}
\end{aligned}
$$

In general, the solution of Nash-type noncooperative conflict game:

$$
\begin{aligned}
& \left(z_{1}^{*}, z_{2}^{*}\right) \text { such that } z_{1}^{*}=\psi_{1}\left(z_{2}{ }^{*}\right) \text { and } \\
& z_{2}^{*}=\psi_{2}\left(z_{1}^{*}\right)
\end{aligned}
$$

cannot be guaranteed, depending upon parameters. Even if the solution exists, it may well be unstable.

\section{EXISTENCE, STABILITY, AND COMPARATIVE STATICS WHEN $P_{M}$ CHANGES}

If the solution to the conflict game exists, it can be computed through Newton method, and comparative statics is possible by changing the values of parameters. In this section, we proceed 
to this topic, examining how utility levels of the 2 LDCs change as the international price of weaponry, $p_{M}$, declines due to oversupply by the old (defunct) Eastern bloc.

We start from the examination of existence and stability. As shown in Figure 1, when $\alpha_{1}=1 / 2$, $\beta_{1}=1 / 3, \quad \gamma_{1}=1 / 4, \quad \alpha_{2}=1 / 2, \quad \beta_{2}=1 / 3, \quad \gamma_{2}=1 / 4, \quad \lambda_{1}=3$, $\lambda_{2}=3, \bar{l}_{1}=200, \bar{l}_{2}=100, p_{1}=1, p_{2}=1, p_{M}=0.1$, there exist no non-cooperative solutions to the conflict game. (Case I).

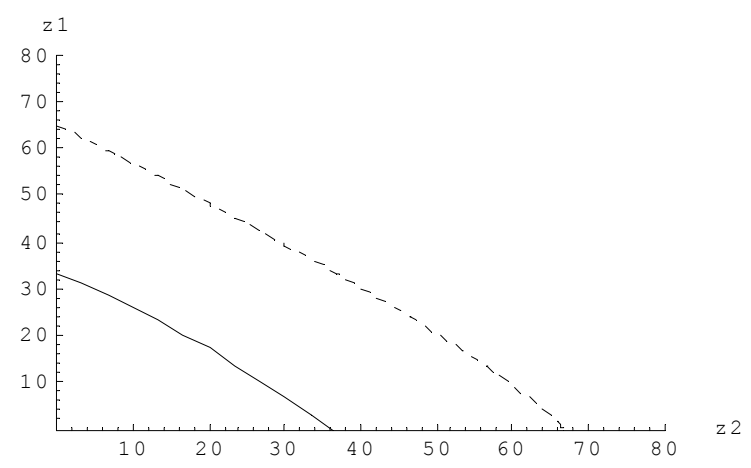

Figure 1. Non-existence case

In this figure, the dashed line exhibits the reaction function of the country $1 ; z_{1}=\psi_{1}\left(z_{2}\right)$, while the solid line exhibits the reaction function of the country $2 ; z_{2}=\psi_{2}\left(z_{1}\right)$.

The non-existence may result from the big difference of population. Starting from the Case I, if $\bar{l}_{1}=\bar{l}_{2}=100$ is assumed, there exists non-cooperative solution to the conflict game. Note, however, that it is an "unstable" solution, as shown in Figure 2. (Case II)

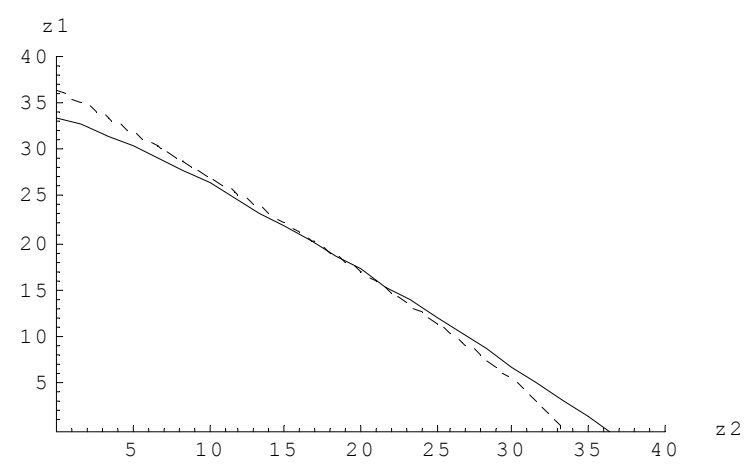

Figure 2. Unstable case: large invasion effect.

The instability may result from the large invasion effect; $\lambda_{1}$ and $\lambda_{2}$. Starting from the Case II, if $\lambda_{1}=\lambda_{2}=2$ are assumed: the reduction of invasion power, there exists a non-cooperative solution to the conflict game, as shown in Figure 3. Note that in this case it is a "stable" solution. (Case III)

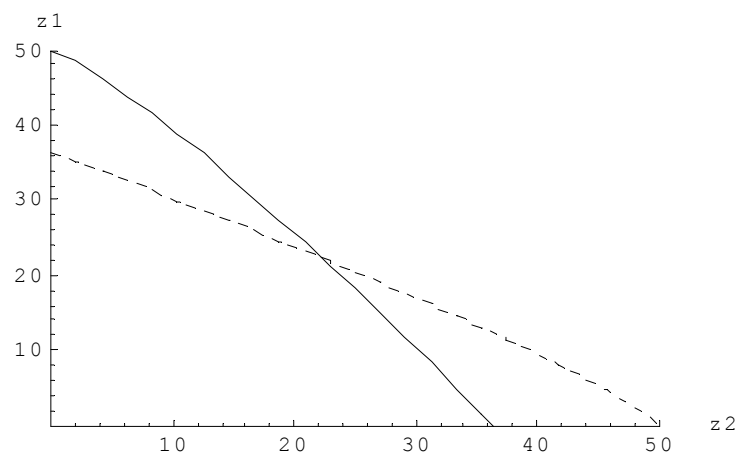

Figure 3. Stable case: small invasion effect.

Alternatively, starting from the Case II, if $p_{M}=1$ is assumed: the rise of the international price of the weaponry, there exists a non-cooperative solution to the conflict game, as shown in Figure 4. Note that in this case it is also the same "stable" solution as in Case III. (Case IV)

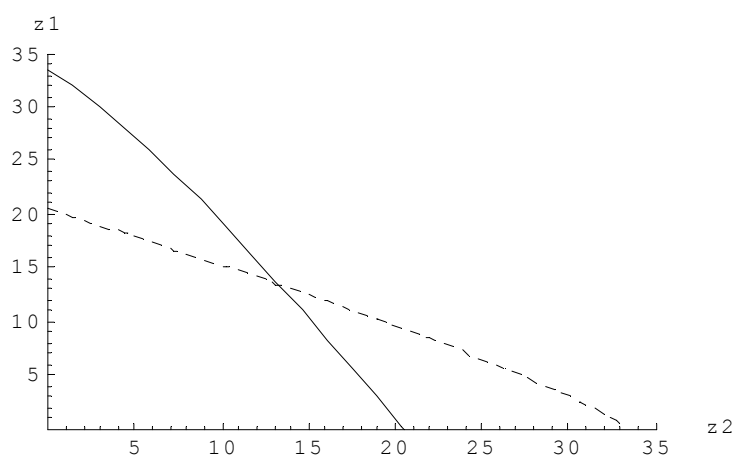

Figure 4. Stable case: high $p_{M}$.

We proceed to the topic of the comparative statics: how utility levels of 2 LDCs change as the international price of weaponry, $p_{M}$, declines due to oversupply by the old (defunct) Eastern bloc. In order to do so we fix parameters other than $p_{M}$ as $\alpha_{1}=2 / 3, \beta_{1}=1 / 3, \gamma_{1}=1 / 4, \alpha_{2}=1 / 2, \beta_{2}=1 / 3$, $\gamma_{2}=1 / 4, \quad \lambda_{1}=2, \quad \lambda_{2}=3, \bar{l}_{1}=120, \bar{l}_{2}=100, p_{1}=1$, and $p_{2}=1$.

Selecting $100 p_{M} \mathrm{~s}$, from 0.1 to 10 with equal difference of 0.1 , we plot the pairs of realized utility levels, $\left\{U_{1}, U_{2}\right\}$, with the conclusion: as $p_{M}$ declines the utility levels of both countries rise at the outset, and when $p_{M}$ becomes sufficiently low, further decline of $p_{M}$ causes the decline of the utility level of country 2 , while the utility level of the country 1 keeps rising, as 
shown in Figure 5. It is checked that all the cases exhibit "stability" of solutions.

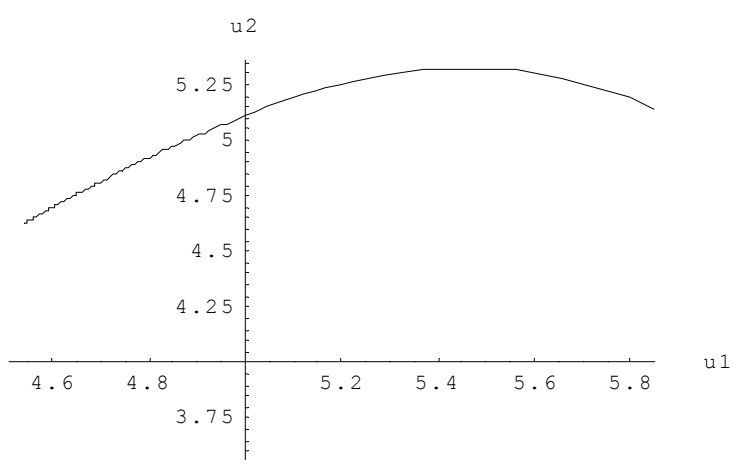

Figure 5. Comparative statics.

In what follows, we construct 10000 conflict games where parameters, $\lambda_{i} \mathrm{~s}, \bar{l}_{i} \mathrm{~s}$, and $p_{M} \mathrm{~s}$ are selected randomly, and (i) compute the percentage of conflict games with positive solutions, (ii) compute the percentage of the stable solutions among the positive solutions, and finally, (iii) compute the percentage of the "2 countries' utility levels rise as $p_{M}$ declines" cases among the stable solutions.

If $\lambda_{i} \mathrm{~s}, \bar{l}_{i} \mathrm{~s}$, and $p_{M} \mathrm{~s}$ are selected randomly, from $\{0,1000000\},\{1,1000000\}$, and $\{0,1000000\}$ respectively, out of 10000 conflict games, (i) about $15 \%$ have positive solutions, (ii) about $95 \%$ of those positive solutions are stable, and finally (iii) about $80 \%$ of the stable solutions are "2 countries' utility levels rise as $p_{M}$ declines" cases.

On the other hand, if $\lambda_{i} \mathrm{~s}, \bar{l}_{i} \mathrm{~s}$, and $p_{M} \mathrm{~s}$ are selected randomly, from $\{0,1000000\}$, $\{1,1000000\}$, and $\{0,1000\}$ respectively, out of 10000 conflict games, (i) only $2 \%$ have positive solutions, (ii) about $90 \%$ of those positive solutions are stable, and finally (iii) about $65 \%$ of the stable solutions are "2 countries' utility levels rise as $p_{M}$ declines" cases.

In this way, we may conclude that as $p_{M}$ declines due to oversupply by the old (defunct) Eastern bloc, (i) the possibility of existence of conflict games falls, (ii) the possibility of stability falls, and finally (iii) the possibility of "utility decline for one of the 2 countries" rises.

\section{EXTENSIONS}

As a conflict game, the game constructed so far is a restricted one. A few extensions of this conflict game are attempted in this section. One of them is concerned with the characteristic of military power, while the other is concerned with the manufacturing of weaponry.

\subsection{Defensive as well as Offensive Military Power}

An extension of the previous model is required from the viewpoint of characteristic of military power. So far, the production function of the $i$-th country is defined by $f_{\mathrm{i}}\left(L_{\mathrm{i}}, z_{\mathrm{j}}\right)=\left(L_{\mathrm{i}}-\lambda_{\mathrm{i}} z_{\mathrm{j}}\right)^{\beta \mathrm{i}}$, which implies the military power of the i-th country plays only offensive role, without playing any defensive one. If it plays the defensive role, $z_{i}$ could reduce the invasion effect of $z_{j}$. Thus, one of the extensions is to modify $\lambda_{i}$ to be a decreasing function of $z_{i}$. Or, another extension is to modify the production function to $f_{\mathrm{i}}\left(L_{\mathrm{i}}\right.$, $\left.z_{i}, z_{\mathrm{j}}\right)=\left(L_{\mathrm{i}}-\operatorname{Max}\left[0, \lambda_{\mathrm{ij}} z_{\mathrm{j}}-\lambda_{\mathrm{ii}} z_{\mathrm{i}}\right]\right)^{\beta \mathrm{i}}$. In this section it is assumed that military power plays both offensive and defensive roles, by adopting the latter approach. In this approach, however, it is almost impossible to determine the optimal value of $z_{i}$, given $z_{j}$. To overcome this computational difficulty, it is assumed that $\lambda_{\mathrm{ij}} z_{\mathrm{j}}-\lambda_{\mathrm{ii}} z_{\mathrm{i}}$ in $f_{\mathrm{i}}\left(L_{\mathrm{i}}, z_{i}, z_{\mathrm{j}}\right)$ is predetermined, and this part does not influence the determination of $z_{i}$, given $z_{j}$. In other words, dynamic element is introduced. Thus, given $\left\{z_{1}(\mathrm{t}-1), z_{2}(\mathrm{t}-1)\right\}$ and $f_{\mathrm{i}}\left(L_{\mathrm{i}}, z_{i}(\mathrm{t}-1), z_{\mathrm{j}}(\mathrm{t}-1)\right)$, reaction function is computed to determine $\left\{z_{1}(\mathrm{t}), z_{2}(\mathrm{t})\right\}$. It is clear that this ad hoc assumption reduces the computational difficulty, since the parametric part, $\lambda_{\mathrm{i}} z_{\mathrm{j}}$, is only replaced by another parametric part, $\operatorname{Max}\left[0, \lambda_{\mathrm{ij}} z_{\mathrm{j}}-\lambda_{\mathrm{ii}} z_{\mathrm{i}}\right]$. This introduction of dynamic element necessitates the analysis of stability.

As a simulation example, suppose that country 1 has population of $1,000,000$ and military power of 3000 units, while country 2 has population of 50,000 and military power of 200 units. If international price of weaponry, $p_{M}$, is 15 , after the 3-rd period, the military power of the country 2 is zero; country 2 is conquered by country 1 . Next, let us start from the same parameters as above, except for $p_{M}$. Suppose that $p_{M}=48.85688$. Even with this high weaponry price, the military power of country 2 continues to decline. At the 10 -th period, country 2 is conquered by country 1 . Finally, let us start from the same parameters as above, except for $p_{M}$. Suppose that $p_{M}=80$. With this high weaponry price, while the military 
power of the country 2 declines at the initial phase, it stabilizes at 7.36249 after the 5-th period. Thus, country 2 escapes from the military occupation by country 1 . (See my home page.)

From this simulation, it is clear that the conclusion in the previous sections holds when both the defensive and offensive characteristic of military power is incorporated; i.e. high international weaponry price, $p_{M}$, is the condition for the conflict games to be stable.

\subsection{Domestic Production of Weaponry}

For simplicity we have assumed that all the military goods are imported from the developed countries. In reality, at least some of them are manufactured in LDCs themselves, and it is well known that there are LDCs who even export the military goods: e.g. Brazil, China, India, Pakistan, etc. From now on, one of the main assumptions in the original model is modified, and according to the modification all the military goods are produced in each LDC in conflict. It is assumed furthermore that those military goods are manufactured under cost-minimization (not profit-maximization). Those labor and commodities required for the production of military goods are guaranteed to be supplied from the private sector by the government. In this sense, the military industries in this section have a characteristic of government-owned firms, and it appears to be typical among the actual LDCs, although some components might be imported from the developed countries in actual world.

Let us explain the formal model in what follows. The most important modification consists in the introduction of military industry, and the 1-st country's production function of military goods is assumed to be

$$
m_{1}=g_{1}\left(L_{M 1}, x_{M 1}\right)=k_{1} L_{M 1}^{\delta 1} x_{M 1}^{1-\delta 1} \quad 0 \leqq \delta_{1} \leqq 1
$$

where $L_{M 1}$ is labor input and $x_{M 1}$ is input of civilian goods while $k_{1}$ is the level of technology. We assume the same production function on the civilian goods as in the original model; i.e. $f_{1}\left(L_{1}, z_{2}\right)=\left(L_{1}-\lambda_{1} z_{2}\right)^{\beta 1}, 0 \leqq \beta_{1} \leqq 1$, while its price is domestically determined in this section. It is assumed that, civilian goods industry, which contains farmland, scattered nationwide without deliberate planning, is more seriously damaged by the enemy's invasion than the military industry.

The military industry behaves so as to achieve the minimization of cost:

$$
\min W_{1} L_{M 1}+p_{1} x_{M 1} \quad \text { s.t. } m_{1}=g_{1}\left(L_{M 1}, x_{M 1}\right) \text {. }
$$

By assumption, these military industry's demands are satisfied by the government. The (aggregate) household's behavior is stipulated as

$$
\begin{aligned}
\max & U_{1}\left(x_{C 1}, z_{1}\right)=x_{C 1}{ }^{\alpha 1} z_{1}{ }^{1-\alpha 1} \quad 0 \leqq \alpha_{1} \leqq 1 \\
& \text { s.t. } z_{1}=m_{1}{ }^{\gamma 1} v_{1}{ }^{1-\gamma 1}, 0 \leqq \gamma_{1} \leqq 1 \\
& p_{1} x_{C 1}+p_{1} x_{M 1}{ }^{\mathrm{d}}=W_{1}\left(\bar{l}_{1-v_{1}-L_{M 1}{ }^{\mathrm{d}}}\right)+\pi_{1}
\end{aligned}
$$

where $x_{C 1}$ is the (1-st country's) household's consumption of civilian commodities.

Through tedious calculation, the number of troops in general equilibrium, $v_{1}{ }^{* *}$, is derived as

$$
\begin{gathered}
v_{1}^{* *}=\left(1-\alpha_{1}\right)\left(1-\gamma_{1}\right)\left(\bar{l}_{\left.1-\lambda_{1} z_{2}\right) /}\left[1-\left\{\alpha_{1}+\gamma_{1}\left(1-\alpha_{1}\right) B_{1 m}\right\}\left(1-\beta_{1}\right)\right],\right.
\end{gathered}
$$

where

$$
\begin{aligned}
& B_{1 m}=\left(\left(1-\delta_{1}\right) / \delta_{1}\right)^{\delta 1 /} / A_{1}, \\
& A_{1}=\left\{\left(1-\delta_{1}\right) / \delta_{1}\right)^{\delta 1-1}+\left(\left(1-\delta_{1}\right) / \delta_{1}\right\}^{\delta 1} .
\end{aligned}
$$

On the other hand, military goods production in general equilibrium, $m_{1} * *$, is derived as

$$
\begin{aligned}
& m_{1}^{* *=} \\
& k_{1} \gamma_{1}\left(1-\alpha_{1}\right) \beta_{1}^{\beta 1(1-\delta 1)} \\
& \left\{\alpha_{1}+\gamma_{1}\left(1-\alpha_{1}\right) B_{1 m}\right\}^{(\beta 1-1)(1-\delta 1)} \\
& \left(\bar{l}_{1}-\lambda_{1} z_{2}\right)^{\beta 1(1-\delta 1)+\delta 1 /} \\
& A_{1}\left[1-\left\{\alpha_{1}+\gamma_{1}\left(1-\alpha_{1}\right) B_{1 m}\right\}\left(1-\beta_{1}\right)\right]^{\beta 1(1-\delta 1)+\delta 1} .
\end{aligned}
$$

The optimal military power, $z_{1} * *$, is defined by $z_{1}^{* *=m_{1} * *} v_{1}^{* *}$, and comparison between (4) and (5) and (6) reveals that essentially the same reaction functions are derived as in the original model.

Here, we may conduct a similar simulation: how the results of existence, stability, and comparative statics change as $k_{1}$ and $k_{2}$ increase. Presumably, the same conclusion as in the case of declining $p_{M}$ would be obtained, thus, this simulation is not attempted in this paper.

\section{CONCLUSIONS}

The aim of this paper was to formulate a two-country model in which two confronting countries intentionally exert external diseconomy upon each other: i.e., they are at war with each other. After deriving the reaction functions in section 2, we examined in section 3 the effect of 
the decline of $p_{M}$ on the "existence" of solution to the conflict game, its "stability", and finally on the utility levels of two countries in the "stability" cases, in terms of simulation. In standard models, if prices fall, indirect utility usually rises. The special feature of the model in this paper consists in the fact that each country's military power causes external diseconomy to the other's production, and the simulation discovers a case in which one country' utility level falls, while the other's utility level rises. By constructing 10000 games through random selection of parameters, we showed that as $p_{M}$ falls, the number of "non-existence" cases increases, the percentage of "instability" cases among "existence" cases rises, and finally as $p_{M}$ falls, the percentage of "rising utility levels of 2 countries" cases among "stability" cases falls. It is well known that military industries do exist in LDCs. In section 4, we modified the original model, such that the above LDCs have domestic military industries, supplying military goods under cost minimization. For simplicity, it is assumed that no import of parts for the military goods production is required. We showed that the reaction functions in this conflict game have similar form as in the ones derived in the original model. Another extension was attempted in this section. In this extension, the defensive characteristics of military power, as well as the offensive one, are incorporated, and similar conclusion on "stability" was derived.

It must be noted that by assumption our model in this paper omits the aspect of human loss by the invasion. (As for the difficulty of evaluating human loss in economics, see Mishan [1971].) In this sense, our conclusion underestimates the negative effect of declining $p_{M}$.

\section{REFERENCES}

Fukiharu, T., "Economics of National Defense-A General Equilibrium Approach", Kobe University Economic Review, vol. 36, 1-36, 1990.

Galbraith, J.K., "The Autonomous Military Power: An Economic View", in The Economics of International Security (ed. by M. Chatterji, H. Jager, and A. Rima), Macmillan, 9-13, 1994.

Klein, L.R., "Development and Disarmament: The Meaning", in The Economics of International Security (ed. by M. Chatterji, H. Jager, and A. Rima), Macmillan, 14-19, 1994.

Klein, L.R., "Some Recent Developments in Global Military Spending", paper presented at the ECAAR Seminar, Tokyo, 1996.

Rapoport, A., "The Application of Game Theory to Peace Research", Impact of Science on Society., 1968.

Mishan, E.J., Cost-Benefit Analysis, George Allen \& Unwin, London, 1971.

Richardson, L.F., Arms and Insecurity, Atlantic Books, 1960. 